\title{
Die spezifische Behandlung der genuinen Pneumonie.)
}

Von Prof. Dr. Carl Klieneberger,

(Dirigierender Arzt des Stadtkrankenhauses Zittau) Stabsarzt d. R., Garnisonarzt i. W.

Die Einwirkung der aktiven Schutzimpfung auf nachfolgende Krankheiten oder gar der Wert einer passiven Immunisierung bei bereits bestehender Infektion wird nicht gleichsinnig beurteilt. Die in der Regel herangezogene Massenstatistik ist persönlicher Erfahrung an kleinem, kritisch studiertem Material unterlegen. Von der Schutzpockenimpfung abgesehen, haben sich als aktive Methoden in größerem Maßstabe nur die Typhusund Choleraimpfung eingebürgert und sind anerkannt. Der Nutzen des passiven Impfschutzes dagegen, selbst bei $\mathrm{Di}$ phtherie, Tetanus und Genickstarre (von Impfung gegen Ruhr, Eitererreger ganz abgesehen), ist noch heute zweifelhaft.

Die Vakzine- und Serumbehandlung der kruppösen Pneumonie, die sich im Anschluß an die Behandlung des Ulcus corneae serpens besonders entwickelte, ist in den letzten Jahren erheblich zurückgetreten. Auch die anfängliche $0 \mathrm{ptochin}$ begeisterung ist im Abflauen. Die Kombination von Serum und Optochin aber ist bisher nur im Tierversuch erfolgreich erprobt (Böhncke).

Die Pneumokokkeneinwirkung während des Verlaufs der kruppösen Pneumonie, vornehmlich zur Zeit der Krise - Bildung von Immunkörpern, Auftreten von Zerfallsprodukten usw. - ist nicht eindeutig geklärt. Untersuchung und Beurteilung sind besonders schwierig. Außer verschiedenen spezifisch agglutinablen Pneumokokken kommen öfters atypische Varietäten vor. Die Prüfung auf Bakteriotropie, als besonders charakteristische Immunitätsreaktion bei Lungenentzündung, aber muß immer mit großen Fehlern rechnen.

Ich habe mich nicht davon überzeugen können, daß die Bakteriämie bei der Pneumonie so häufig vorkommt, wie Jochmann es beschrieben hat (70\% der Fälle). Regelmäßig nur findet sich Bakteriämie bei sterbenden Pneumonikern, analog dem Bakterienüberwuchern bei anderen bakteriellen Infektionen. Als Wirkung der Pneumokokken bei der Lungenentzündung sind von Klinikern Autolyse der Lunge mit ungünstiger Kreislaufbeeinflussung, Giftbildung der Kokken während des Lebens im Organismus und Giftwirkung der Kokken

1) Klinischer Vortrag. 
nach dem Absterben (extrahierte oder gelöste Leibessubstanzen) beschrieben. Echte. Pneumokokkentoxine sind dem Bakteriologen nicht bekannt. Die festgestellte Giftigkeit der Leibessubstanz ist sehr gering. Aggressinbildung der lebenden Kokken gilt für zweifelhaft, antiopsogene Wirkung aber erfolgt, wie bei jedem pathogenen Bakterium, im Kampfe mit dem Wirtsorganismus. Pnelumokokkenimmunsera wirken bakterizid und bakteriotrop. Die bakterizide Wirkung scheint ohne wesentliche Bedeutung zu-sein, während der Bakteriotropie der dominierende Effekt zukommt. (Neufeld, Neisser-Gins.)

Es ist somit eine klinische These, daß während der Krise Ent giftung des Organismus und Vernichtung der Kokken statthat, oder daß die Krise durch Eintritt der Unempfindlichkeit gegen die hypothetischen Pneumokokkengifte erfolgt.

Bakteriologisch begründet ist die Auffassung, daß sich im Blute Genesender von der Krise ab Antikörper finden und daß im Blute immunisierter Tiere gewöhnlich dieselben Serumschutzstoffe, unter anderen agglıtinierende, präzipitierende, lytische und opsonogene Immunsubstanzen nachweisbar werdell. Besonders das Ansteigen des opsonischen Index zur Zeit der Krise, die Bildung Phagozytose befördernder Substanzen bei günstig verlaufender Krankheit ist anerkannt.

Die Ergebnisse der Tierversuche und die Erfahrungen bei der Pneumonie des Menschen, einerlei ob Vakzination oder Serumimmunisierung gewählt werden, sind nur sehr bedingt vergleichbar. Beim Menschen ist zunächst die infizierende Kokkenart gänzlich unbekannt. Im Experiment dagegen gelangen genau charakterisierte Stämme zur Anwendung. Die Beeinflussung dieser durch homologe Lösung, Extrakte oder Antisera ist abstufbar. Vorausgehende oder nachfolgende Infektion kann geprüft und kontrolliert werden. Dazu ist der Krankheits. ablauf beim Menschen und Tier fundamental verschieden, von Verlauf eigentümlichkeiten, natürlicher Resistenz der verschiedenen Tiergattungen abgesehen (Kolle - Hets ch). Beim Menschen ist die Pneumokokkeninfektion in der Regel eine lokale Erkrankung, beim Versuchs tier verläuft sie als akute septische Allgemeininfektion gelegentlich und nur bei geringer Virulenz der Kokken mit begleitender Lokalisierung. Die Einwirkung von therapeutischen Maßnahmen aber auf septische Allgemeininfektion ist leichter und sicherer als dje auf Lokal erkrankungen zu erkennen und protokollarisch festzulege $\eta$. Berück sichtigt man zudem, daß die menschliche Pneumonie häufig in den ersten Tagen nicht erkannt wird und meist in einer Woche abläuft, so wird man von der aktiven Immunisierung nicht zu viel er warten dürfen. Immerhin wollen Rosenow und Hektoen durch Injektion ausgelaugter Pneumokokken, sowie Hirschfelder durch Einspritzung angedauter Bakterien günstige bzw. ermutigende Erfolge bei der Pneumonie erzielt haben. Ueber den Erfolg prophylaktischer Vakzination liegen keine Angaben vor. Während demnach die aktive Immunisierung des Menschen über erste Ansätze nicht hinausgelangt ist, liegen über passiven $I m p f s c h u t z$ vielfältige Versuche und großes Literaturmaterial vor.

Im Tierversuch schützt vorausgehende Seruminjektion gegen nachfolgende, sonst sicher tödliche Infektion des homologen Stammes (Neufeld. Händel, Böhncke). Auch bereits manifeste Erkrankung kann durch rechtzeitige Anwendung des homologen Immunserums erfolgreich bekämpft werden (Lamar). Bei den ersten Krankheitsprozessen des Menschen indessen wird der Expelimentalforderung, frühzeitig hohe Dosen homologen Heilserums zu verabfolgen, nur ausnahmsweise Rechnung getragen werden können. Infolgedessen wurde empfohlen, möglichst frühzeitig intravenös hohe Dosen sogenannter polyvalenter Sera prophylaktisch oder zu Heilzwecken zu applizieren. Kritische Erfahrungen über prophylaktische passive Immunisierung, etwa nach Operation bei älteren Leuten, liegen in größerem Maßstabe nicht vor.

Ueber Serumimmunisierung bei Pneumonie freilich ist eine zahlreiche Kasuistik vorhanden. Der experimentell festgelegten Anforderung indessen, bei den Pneumokokkenerkrankungen, zumal bei der Pneumonie, therapeutisch große Gaben sogenannten polyvalenten Sarums anzuwenden, genügen eine Rihe von Literaturmitteilungen nicht ( $G$. und F. Klem perer, $\mathrm{Cux}, \mathrm{Krische,} \mathrm{Jelke,} \mathrm{Baermann).} \mathrm{Trotz-}$ dem werden Erfolge verzeichnet. Unter den anderen Autoren, deren Technik den Prämissen entspricht, bestehen erhebliche Meinungsverschiedenheiten über den Erfolg der Seruminjektion.

Während u. a. Tauber, Rodenwaldt, Paessler, Beltz, Gér on ne, Newjadomski, Willia ms mehr oder weniger energisch für die Serumbehandlung der Pneumonie (polygenès Römer-Serum, s. Neufeld-Händel-Serum) eintreten, bezeichnen Fraenkel, Siebeck, Gross, Lindenstein und Knuth, Dorendorf, Rieder diese Therapeutik als unsichere oder nicht brauchbare Heilmethode. Zu dieser Kritik haben, neben der Schwierigkeit der sicheren Beurteilung, Anfangsversager, häufiger auch an die Injektion anschließende akut bedrohliche Allgemeinerscheinungen sowie anaphylaktische Serumwirkungen beigetragen. Dazu mag noch bei skeptischen Untersuchern die theoretische Betrachtung kommen, daß auf den lokalen Prozeß der Hepatisation, mit veränderter Blut- und Saftströmung, nicht eingewirkt werden könne und daß Allgemeinwirkung nach dem Ergebnis bakteriologischer Forschung zweifelhaft sei.

Für die Beurteilung der Einwirkung großer Dosen sogenannten polyva lenten Serums auf ausgebildete Pneumokokken. erkrankungen des Menschen, gemeinhin auf die kruppöse Pneumonie, fehlen objektiv eindeutige Anhaltspunkte. ${ }^{1}$ ) Es ist fehlerhaft, als Kriterium der Serumwirkung das Verschwinden der Kokken aus dem Blute anzunehmen (Weitz). Die Bakteriämie bei der Pneumonie ist kein regelmäBiges Attribut der Krankheit. Die Pneumokokken finden sich im Blute meist nur vereinzelt, häufig ganz vorübergehend, abgesehen davon, daß der Nachweis der Pneumokokken oft aus äußeren Grühden mißlingt. Laukozytenveränderung aber als Kriterium erfolgreicher Immunisierung zu betrachten, ist nicht möglich. Die Leukozytenzahlen bei der Pneumonie, selbst bei demselben Individuum, schwanken mitunter in weiten Grenzen. Dazu ist Leukozytose nach Seruminjektion an sich $\mathrm{zu}$ erwarten. Besondere charakteristische Veränderungen im Blutbilde aber nach Immunisierung von Pneumonikern habe ich nicht feststellen können.

So muß die Beurteilung des therapeutischen Erfolges passiver Impfung subjektiv nach klinischem Ermessen erfolgen. Dabei ist in der Literatur der Tatsache, daß große Serum. gaben vorübergehende Temperatursenkung zur Folge haben und an sich im Sinne von Ehrlich als Ietus immunisatorius wirken, nicht genügend Rechnung getragen.2) Sonst gelten mit Recht als Anhaltspunkte für die Beurteilung des Heilerfolges die Abkürzung der Krankheit durch beschleunigtes Eintreten der Krise, die Abnahme der Krankheitsschwere, insbesondere durch Besserung des Allgemeinbefindens, das Absinken der Mortalitätsziffer, das Verschontbleiben von Komplikationen. Bai einer Krankheit freilich, die im allgemeinen, bei jeder und trotz jeder Therapie" (Eichhorst) ausheilt, dürfte nur eine Massenstatistik die unvermeidlichen Fehler der Beurteilung einschränken können. Die statistische Aufnahme müßte zudem noch gleichartige Individuen an gleichem Orte bei kurzer Ziitspanne umfassen. Das ist bei der Pneumonie mit notorischem Wechsel des Verlaufs bei verschiedenen Altersklassen, in verschiedenen Jahreszeiten, an verschiedenen Orten und Krankenanstalten kaum möglich.

Mein trotzdem für rein klinische Beurteilung der therapeutischen Einwirkung, ,polyvalenten" Römer-Sərums herangezogenes Material beziffert sich auf 55 Fälle.

35 Fälle, die innerhalb zwei Jahren im Krankenhause bzw. im Lazarett zu meiner Beobachtung gelangten, wurden spezifisch (34 mal polygenes Römer-Serum, 1 mal Neufeld-Händel-Serum) ${ }^{3}$ ) behandelt. Vergleichsweise, zum Teil aus äußeren Gründen, wurden weitere 20 Erkrankungen in zwei anderen Jahren nicht spezifisch, sondern rein symptomatisch behandelt. In beiden Reihen hatte keinerlei Auswahl statt. In der ersten Serie wurde bei sämtlichen Pneumoniezugängen gespritzt, in der anderen bei allen. Lungenentzündungs. aufnahmen nur nach allgemeinen Gesichtspunkten verfahren. Meine besondere Stellungnahme auf Grund einer Serumbehandlungsreihe von 35 Fällen ist gerechtfertigt, weil bei meinem. Material stets der Pneumokokkennachweis (vielfach Prüfung der herangezüchteten Kulturen im Tierversuch) erbracht wurde, weil die Serumbehandlung stets intravenös mit großen Dosen erfolgte und häufig sehr frühzeitig einsetzen konnte. Fast alle sonst vorliegenden Literaturerfahrungen übrigens beziehen sich auf eine erheblich kleinere Kasuistik (!) und sind nicht bakteriologisch kontrolliert (verschiedene Erreger!).

Die intravenöse Serumapplikation ${ }^{4}$ ) bei klinisch sichergestellter Pneumonie konnte in nahezu der Hälfte der Fälle innerhalb der ersten drei Krankheitstage, mitunter schon sechs Stunden nach dem initialen Schüttelfrost einsetzen. Das war nur möglich, weil mir für diese Unter. suchungen das Material des Garnisonlazaretts meiner Friedenstätigkeit zugänglich gemacht ${ }^{5}$ ) worden war (ein Drittel der Kasuistik).

1) Kontrolluntersuchungen mit Injektionen von Normalpferdeserum sind nicht angestellt. - $\left.{ }^{2}\right)$ Siehe vorige Note. - 3) Spät einsetzende Behandlung ohne sichtbare Einwirkung auf die sich vorbereitende kritisch-lytische Entfieberung oder den weiteren Verlauf. - 4) Polygenes Pneumokokkenserum Merck, das mir von der wissenschaftlichen Abteilung Merck in ausgiebiger Weise zur Verfügung gestellt wurde. - ${ }^{5}$ ) Durch Stabsarzt Dr. Ts ch ö ts chel. 
Bei den Soldaten erfolgte die Lazarettaufnahme unmittelbar nach dem zur Krankmeldung führenden Fieberparoxysmus. Bei der Zivilbevölkerung war meist eine Reihe von Tagen vergangen, ehe die Krankenhauseinweisung od.er die Krankenhausaufnahme erfolgte. Dies wird auch bei anderen Krankenanstalten in der Regel der Fall sein. So wird meist eine frühe spezifische Behandlung in den Stadtkrankenhäusern unmöglich.

Die Seruminjektionen erfolgten an einander folgenden Tagen und. wurden nur ausnahmsweise am gleichen Tage wiederholt. Die Einzeldosis betrug in der Regel 10-20 ccm, d. h. 200-400 E.I. Bei d.em Einzelfalle gelangten mithin meist $30-50 \mathrm{ccm}$ Serum oder 600 bis 1000 I.E., vereinzelt auch $60 \mathrm{ccm}$ Serum, d. h. 1200 I.E. zur Anwendung. Die spezifische Behandlung wurde mit einsetzender Entfieberung unterbrochen.

Unter 18 so innerhalb der ersten drei Krankheitstage Behandelten entfieberten $12 \mathrm{Kranke}$ definitiv vor Ablauf des 7. Krankheitstages. Dabei trat in vier Fällen die Deferveszenz im Laufe der vier ersten Krankheitstage ein. Bei d.en aus der Zahl 18 verbleibenden 6 Kranken alierdings erfolgte die Krise erst am 7. Tage, verschleppte sich oder erfolgte kritisch-lytisch bis zum 10. Krankheitstage. Hierunter fallen 3 Beobachtungen bei Soldaten, deren spezifische Behandlung am 1. Krankheitstage oder am Beginn des 2. Krankheitstages begonnen hatte. Nur ausnahmsweise erfolgte die Entfieberung in rasche Krise. Das Fieber fiel gewöhnilch iytisch ab oder nach einer Anfangssenkung durch ein subfebriles Zwischenstadium, sodaß die Entfieberung sich auf 2 bis 3 Tage verteilte. Ungünstige Einwirkung der Injektion auf das Aligemeinbefinden habe ich, abgesehen von einem Anfalle von Anaphylaxie, eine Woche nach der ersten Injektion (der betreffende Kranke war vor knapp einem halben Jahre mit Pneumokokkenserum gespritzt) ${ }^{1}$ ), nicht beobachtet. Die nicht seltene vorübergehende Tem. peratursenkung als Folge der Seruminjektion als solcher wurde durchaus angenehm empfunden. Die sonst meist geäußerte subjektive Angabe - und das gilt besonders für frühgespritzte Mannschaften daß nach der ersten Injektion schon eine Besserung sich fühlbar machte, möchte ich nicht $\mathrm{zu}$ hoch bewerten. Immerhin stimmten Angaben und Beobach,tungseindruck der mitbehandelnden Aerzte überein. Von diesen 18 frühbehandelten Kranken ist keiner gestorben, die einzigen Komplikationen waren eine leichte Pleuritis und eine kurzdauèrnde Amentia. Bei dem Restbestande von 17 Kranken hatte ich wiederholt den Eindruck, daß nach Seruminjektion die Entfieberung früher, mitunter schon vom sechsten Krankheitstage ab, einsetzte, daß der gesamte Krankheitsprozeß günstiger verlief, mindestens daß eine subjektive Besserung angegeben wurde. Das veranlaßte mich, auch zweimal das Mittel bei chronischer Lungentuberkulose mit Pneu moniekomplikation und je einmal bei zwei sich lange hinziehenden Pneumonien sowie bei einer chronischen subfebrilen Pneumokokkeninfektion der Luftwege zu versuchen. Das Ergebnis erschien günstig bzw. Seruminjektion und Genesung sclilossen zeitlich aneinander an. Die Komplikationen indessen, wie Amentia (zwei Fälle), Pleuritis und Empyem (je einmal), scbienen in ihrer Entwicklung nicht beeinflußt $\mathrm{zu}$ werden.

Aus dieser ganzen Serumreihe von 35 Fällen sind nur 2 Kranke gestorben $(2: 35=5,7 \%)$. Die betreffenden Patienten von 30 und 36 Jahren waren am 5. Krankheitstage mit Wanderpneumonie und Delirium sowie mit rechtseitiger Totalpneumonie zur Aufnahme gelangt und sind am 7. bzw. 8. Krankheitstage nach Anwendung von jeweils $40 \mathrm{ccm}$ Serum $=800$ I.E. ad exitum gelangt.

Allgemein gewann ich den Eindruck, daß, zumal im Gefolge beschleunigter Entfieberung, eine vermehrte Neigung zu Rekonvaleszenzfieberzacken oder zur Ausbildung subfebriler Perioden auftrat. Meist schlossen an die Entfieberung einzelne Tage mit abendlichem Fieber bis $38,6^{\circ}$, gelegentlich auch eine Reihe von Fiebertagen bis $38,2^{\circ}$ mit und ohne Unterbrechung durch Afebrilität. Diese Fieberbereitschaft bestand nicht nur bei Kranken, deren spezifische Behandlung innerhalb der ersten drei Tage begonnen hat $(7: 18)$, sondern auch bei solchen, die später gespritzt waren (5: 17). Diese neue Erfahrung möchte ich als Folge der Serumbehandlung ansehen, ohne mich zur Genese theoretisch zu äußern.

Ueber die Vergleichsreihe $\nabla 0 n 20$ nach allgemeinen Gesichtspunkten symptomatisch behandelten Fällen von Lungenentzündung in extenso zu berichten, erübrigt sich. Mein Eindruck, das stelle ich voran, war der, daß bei der Serumreihe die Krankheit, zumal bei früher Behandlung, rascher und günstiger ablief als in der rein symptomatisch behandelten Reihe. Mehr als die Hälfte dieser Kranken - über ein Drittel Soldaten - gelangte innerhalb der ersten drei Krankheitstage zur Krankenhausbehandlung. Solche Frühaufnahmen wurden vollständig hergestellt entlassen. Von den anderen,

1) Beobachtung von kruppöser Pneumonie mit Neuerkrankung der andern Seite nach nicht einem halben Jahre. später zugegangenen Pneumonien sind drei - die Aufnahme erfolgte erst nach Ablauf der ersten Krankheitswoche - verstorben (3:20 $=15 \%$ ).

Danach wirkt die frühzeitige Behandlung der kruppösen Pneumonie mit polygenem Pneumokokkenserum in großen Dosen günstig auf das Allgemeinbefinden, im besonderen a f den Fieber ablauf ein. Die ausreichende Serumanwendung in den ersten Krankheitstagen verkürzt häufig um mehrere Tage dieFieberperiode und wahrscheinlichauch den ganzen KrankheitsprozeB. Eine Einwirkung auf den Ablauf und die Ausbildung von Komplikationen scheint nicht sicher stattzufinden. Eine Entscheidung, ob eine Beeinflussung der Mortalitätskurve statthat, möchte ich nur auf Grund größerer Statistik treffen. Sicherlich kann die Abkürzung der Kontinua nur günstig einwirken.

Späte Serumapplikation - nach dem fünften Krankheitstage - erscheint mitunter geeignet, chronische Pneumokokkeninfektion erfolgreich zu beeinflussen. Die Serumbehandlung disponiert zu leichten Fiebersteigerungen in der frühen, vielleicht auch späteren Rekonvaleszenz. Völlige Versager der Serumtherapie bei vorschriftsmäßiger Anwendung im Krankheitsbeginne sind nicht selten (mindestens ein Sechstel der Fälle).

Die Pneumokokkenserumbehandlung der Pneumonie setzt im allgemeinen früheste Krankenhausbehandlung voraus. Im Krankenhause wird die intravenöse Injektion a uch von $20 \mathrm{ccm}$ Serum als Einzeldosis und wiederholt keine besonderen Schwierigkeiten bereiten. Praktisch brauchbar ist allerdings eine derartige Methode nicht. Für die praktische Frühbehandlung.der Pneumonie und für die Beurteilung der Methode in großem Maßstabe wäre ss nötig, stärkere Sera, etwa 400 I.E. in $5 \mathrm{ccm}$, zur Verfügung zu haben. Erwünscht wäre weiter die Laboratoriumsprüfung der bei Serumversagern gewonnenen Pneumokokkenstämme und ihre eventuelle Weiterverwendung zur Tierserumgewinnung. Ob das möglich ist, kann ich nicht beurteilen.

Man wird gemeinhin in Praxis und Krankenhaus, zumal nach Ablauf der ersten drei Krankheitstage, von der Serumbehandlung der Pneumonie Abstand nehmen und Abstand nehmen können. Der Versuch, frühzeitig besonders schwere Fälle passiv zu immunisieren, ist sicher jetzt schon berechtigt. Wie weit später nach Ausbau der Serumdarstellung die Methode der Serumanwendung als therapeutisches und prophylaktisches Heilverfahren sich einbürgern wird, entzieht sich einstweilen der Beurteilung. Heute bereits sind Heilversuche mit Serumanwendung bei den therapeutisch undankbaren chronischen Pneumokokkenerkrankungen, bei der seltenen Pneumokokkensepsis und Pneumokokkenmeningitis durchaus indiziert. 